\title{
Low intensity surplus activated sludge pretreatment before anaerobic digestion
}

\author{
Jan Suschka, Klaudiusz Grübel ${ }^{*}$ \\ University of Bielsko-Biala, Poland \\ Faculty of Materials, Civil and Environmental Engineering, \\ Institute of Environmental Protection and Engineering
}

*Corresponding author's e-mail: kgrubel@ath.bielsko.pl

\begin{abstract}
Keywords: anaerobic sludge digestion, biogas production, sludge disintegration, disintegration degree, hybrid pre-treatment.
\end{abstract}

\begin{abstract}
Sewage sludge (municipal, or industrial) treatment is still a problem in so far that it is not satisfactorily resolved in terms of cost and final disposal. Two common forms of sludge disposal are possible; the first being direct disposal on land (including agriculture) and the second being incineration (ash production), although neither of these methods are universally applied. Simplifying the issue, direct sludge disposal on land is seldom applied for sanitary and environmental reasons, while incineration is not popular for financial (high costs) reasons. Very often medium and large wastewater treatment plants apply anaerobic digestion for sludge hygiene principles, reducing the amount to be disposed and for biogas (energy) production. With the progress in sewage biological treatment aiming at nutrient removal, primary sludge has been omitted in the working processes and only surplus activated sludge requires handling. Anaerobic digestion of waste activated sludge (WAS) is more difficult due to the presence of microorganisms, the decomposition of which requires a relatively long time for hydrolysis. In order to upgrade the hydrolysis effects, several different pre-treatment processes have already been developed and introduced. The additional pre-treatment processes applied are aimed at residual sludge bulk mass minimization, shortening of the anaerobic digestion process or higher biogas production, and therefore require additional energy. The water-energy-waste Nexus (treads of) of the benefits and operational difficulties, including energy costs are discussed in this paper. The intensity of pre-treatment processes to upgrade the microorganism's hydrolysis has crucial implications. Here a low intensity pre-treatment process, alkalisation and hydrodynamic disintegration - hybrid process - were presented in order to achieve sufficient effects of WAS anaerobic digestion. A sludge digestion efficiency increase expressed as $45 \%$ biogas additional production and $52 \%$ of the total or volatile solids reduction has been confirmed.
\end{abstract}

\section{Introduction}

The first stage of anaerobic digestion, the hydrolysis step, is regarded as the rate limiting in the degradation of complex organic compounds, including microorganism's disruption, present in WAS. The limiting decomposition of sludge (35-45\% reduction in volatile solids - VS) is caused by limiting access to the complex organic material which is enclosed in the microbial cell wall or enmeshed in an extracellular polymeric matrix (Wang et al. 2016).

Therefore, several techniques are proposed and investigated to upgrade the effects of organic decomposition by introduction of pre-treatment hydrolysis. Some of the techniques have already been introduced on full technical scale, while thermal, chemical, biological and mechanical processes have been developed (Carrère et al. 2010). In the full scale of wastewater treatment processes probably based on technologies of sonification and mechanical disintegration are most commonly used disintegration techniques.

Probably the most promising techniques are based on the phenomenon of hydrodynamic cavitation (HC) evocation. Under specific conditions of water flow through a constriction, like a valve, Venturi or Lavale nozzle, or even orifice plates (simple holes - perforated plates), a drastic pressure reduction occurs in the outflow. Dissolved air appears as micro-bubbles, which implode at high temperature and pressure. Produced hydroxyl radicals with local high temperature allow for the decomposition of complex organic substances. The HC phenomenon in application to activated sludge disintegration - cell structure disruption - has been investigated by many authors (Kalogo and Monteith 2008). Lee and Han (2013) reported that formed hydroxyl radicals generated during cavitation processes had a high oxidation potential $(\mathrm{E}=2.80)$ and the ability to destroy microorganism's cells. 
Hydrodynamic cavitation is a relatively low power consumption process. As presented by Kalogo and Monteith (2008), the energy demand is in the range of 0.94 to $1.85 \mathrm{kWh} / \mathrm{m}^{3}$. For example, using the same source of data (Kalogo and Monteith 2008), the power consumption of the ultrasonic technology is about $3.7 \mathrm{kWh} / \mathrm{m}^{3}$. The phenomenon of cavitation is also associated with the process of ultrasound disintegration and has been widely investigated and introduced in practice.

The chemical disintegration (used acids, alkalis or oxidants), in turn, is probably the simplest process for particulate organic matter hydrolysis (Ariunbaatar et al. 2014). The effects of $\mathrm{pH}$ decrease or increase on WAS have been studied by many authors (Kim et al. 2007, Li et al. 2008). Chen et al. (2007) investigated the effect of $\mathrm{pH}$ from 4.0 to 11.0 during WAS hydrolysis. They concluded that under alkaline conditions, the VFA's production was significantly higher than under other conditions. However, there was no methane generation after keeping pH on the level of 10.0 and 11.0. Li et al. (2008) confirmed high effectiveness of alkaline conditioning by sodium hydroxide (dosage of $0.2 \mathrm{~g} / \mathrm{g}$ VS), aided by ultrasonic field (ultrasonic pre-treatment). Şahinkaya and Sevimli (2013) achieved sludge disintegration of $24.4 \%$ after using only $\mathrm{NaOH}$ as a disintegrating agent. Kim et al. (2003) conducted alkaline pre-treatment at $\mathrm{pH} 12$ at ambient temperatures. The chemical oxygen demand (COD) solubilisation values after $\mathrm{NaOH}$, $\mathrm{KOH}, \mathrm{Mg}(\mathrm{OH})_{2}$ and $\mathrm{Ca}(\mathrm{OH})_{2}$ addition were 39.8, 36.6, 10.8 and $15.3 \%$, respectively. Similarly, the treatment at $121^{\circ} \mathrm{C}$ for 30 min, $\mathrm{NaOH}$ addition resulted in $51.8 \%$ COD solubilisation. The values for other agents were as follows: $47.8 \%, 18.3$ and $17.1 \%$, for $\mathrm{KOH}, \mathrm{Mg}(\mathrm{OH})_{2}$ and $\mathrm{Ca}(\mathrm{OH})_{2}$, respectively.

Similar results were obtained by Wonglertarak and Wichitsathian (2014), They concluded that the SCOD increased when $\mathrm{pH}$ values were increased. However, the $\mathrm{BOD}_{\text {total }} / \mathrm{COD}$ ratios were decreased for adjusted $\mathrm{pH} 10$ and $\mathrm{pH}$ 11. The adjusted $\mathrm{pH} 8$ showed the optimization for alkaline pre-treatment with increasing SCOD and maximizing $\mathrm{BOD}_{\text {total }} / \mathrm{COD}$ ratios. In alkaline pre-treatment, thermophilic anaerobic condition removed $42.16 \%, 43.15 \%$ and $50.64 \%$ for total solids (TS), VS and COD, respectively, and provided higher efficiency and gas production when compared to other conditions.

Chemical sludge conditioning in combination with other disintegration technologies, like ultrasound or thermal treatment (low temperature between 50 and $70^{\circ} \mathrm{C}$ ), has also been investigated (Ariunbaatar et al. 2014). In the literature, the increase of soluble chemical oxygen demand (SCOD) or the decrease of volatile solids, especially during alkaline treatment in combining with thermal treatment, are stressed (Li et al. 2012).

Rafique et al. (2010) reported that alkaline pre-treatment coupled with thermal methods at a lower temperature $\left(70^{\circ} \mathrm{C}\right)$ could result in a higher (78\%) biogas production with a higher $(60 \%)$ methane content as compared to the best results (28\% increase of biogas production with $50 \%$ methane content) obtained by thermal pre-treatment at higher temperatures $\left(>100^{\circ} \mathrm{C}\right)$.

Sambusiti et al. (2013) made an experimental investigation related to comparisons of different pre-treatments to increase methane production from two agricultural substrates. Thermal, alkaline and thermo-alkaline pre-treatments were performed in batch mode to enhance the methane production from ensiled sorghum forage and wheat straw. Alkaline pre-treatment was conducted at $40^{\circ} \mathrm{C}$ for 24 hours with the addition of $1 \%$ and $10 \% \mathrm{NaOH} / \mathrm{g} \mathrm{TS}$. Thermal and thermo-alkaline pre-treatments were performed at $100^{\circ} \mathrm{C}$ and $160^{\circ} \mathrm{C}$ for $30 \mathrm{~min}$, with and without the addition of $\mathrm{NaOH}$ solutions. These pre-treatments resulted in solubilisation of the organic matter, with a maximum concentration (around 30-40\% for both substrates) obtained at $40^{\circ} \mathrm{C}$ and $100^{\circ} \mathrm{C}$ with $10 \% \mathrm{NaOH}$. The pre-treatments were found to be sustainable for both substrates, especially for wheat straw, due to a higher methane yield increase than that of sorghum.

Kopp and Evert (2006) used saturated steam at a temperature of $165^{\circ} \mathrm{C}$ at $600 \mathrm{kPa}$ pressure, for 30 min without any addition of chemicals. Higher temperatures up to $190^{\circ} \mathrm{C}$ are regarded as high intensity or extreme processes. Apart from high investment and operational costs related to the complex system of heat and energy recovery, that technology has some drawbacks. In addition, it has been documented that thermal pre-treatment of sludge is responsible for the formation of refractory dissolved organic compounds (Climent et al. 2007). Among other refractory compounds, melanoidin has been hypothesized to be produced, resulting in a dark brown liquor (Penaud et al. 2000). After commissioning of the CAMBI process at the treatment plant Oxley Creek - Australia (Dwyer et al. 2008), a distinctive increase of colour and dissolved nitrogen was experienced. The colour produced during the thermal hydrolysis of waste activated sludge was found to be highly dependent on the operating temperature of the process (Dwyer et al. 2008). Additionally, the process was found to be not odourless.

Li et. al. (2013) made an experimental analysis on alkaline post-treatment for improved sludge anaerobic digestion. In this experimentation, $5 \%$ of sludge was extracted from a semi-continuous digester with a sludge retention time of 20 days, between the eighth and the twelfth hour of a 24-hours digestion cycle. The sludge was then disintegrated with $0.1 \mathrm{~mol} \mathrm{NaOH} / \mathrm{L}$ and returned to the digester after neutralization. The post treatment resulted in a $33 \%$ enhancement of biogas production in comparison with the control. The change in recycled sludge up to $10 \%$ or $15 \%$ led to a reduction in biogas yield. Alkaline post-treatment had a minimal impact on the dewaterability of digested sludge.

Chemical treatment in combination with hydrodynamic disintegration was found to be the optimal technology for anaerobic WAS digestion enhanced by low intensive sludge pre-treatment. In order to assess the optimal conditions, it has to be stressed that both processes - chemical treatment (alkalisation) and hydrodynamic disintegration - can be readily adjusted by changes of the dose of chemicals or the timing of the disintegration procedure. The developed technology is simple, has high flexibility of operation with very limited installations or changes in the existing equipment.

Alkali (especially used $\mathrm{NaOH}$ ) weakens the cell walls, making them more susceptible to lysing in the processes of hydrodynamic disintegration. The alkali/acidic pre-treatment methods are relatively simple, energy efficient and contribute to the killing of pathogens (Sakiyama et al. 2011, Silva et al. 2013). As demonstrated, disintegration effects are possible with the addition of relatively small amounts of alkali.

The achieved synergistic effect of the developmental processes - alkali combination with hydrodynamic disintegration allowed the technology to be denominated as a hybrid technology. 
So far, very limited information has been available on alkaline treatment at ambient temperature range, and even less information exists on the hybrid chemical and mechanical treatment - known as the hydrodynamic disintegration approach. The aim of the research work was to asses the combination of alkaline treatment and $\mathrm{HC}$ would increase the soluble chemical oxygen demand (SCOD) value and upgrade the effectiveness of anaerobic sludge digestion in terms of biogas production and sludge minimisation. Additionally, efforts were made to determine the impact of these methods on the performed digestion in mesophilic (first step, MAD), followed by thermophilic (second step, TAD) conditions.

It was assumed that the combination of alkaline treatment and hydrodynamic cavitation would increase the soluble chemical oxygen demand (SCOD) value and upgrade the effectiveness of anaerobic sludge digestion in terms of biogas production and sludge minimisation. The aim of the presented paper was to demonstrate the possibilities of achieving very good results at low cost of equipment and operation. Additionally, the digestion was performed in mesophilic (first step, MAD), followed by thermophilic (second step, TAD) conditions.

\section{Materials and methods}

\section{Sludge samples}

The waste activated sludge (WAS samples, concentration of suspended solids (SS) on average $9.7 \mathrm{~g} / \mathrm{L}$ ) was taken from the secondary settling tanks of municipal wastewater treatment facility (located in the south of Poland) and used as a research material. The amount of treated wastewater by WWTP is approximately $90,000 \mathrm{~m}^{3} / \mathrm{d}$. Concentration of mixed liquor suspended solids (MLSS) fluctuates between 4.3-4.7 g/L and the solid retention time (SRT) is about 14 days.

\section{Alkaline sludge treatment plus hydrodynamic disintegration}

The WAS disintegration was performed as a hybrid method in two steps: first - chemical lysis of microorganisms cells, second - hydrodynamic disintegration. For chemical cell lysis - 2M sodium hydroxide $(\mathrm{NaOH})$ was used. The pre-treatment reactor was mixed continuously and the alkali was simultaneously added in the amount sufficient to keep the selected $\mathrm{pH}$ (in the range of 8-12) during the entire period of $30 \mathrm{~min}$. The amount of $8.95-67.33 \mathrm{mmol} \mathrm{NaOH}(2 \mathrm{M})$ per litre of WAS was added to obtain the desired $\mathrm{pH}$ value 7.16-12.10, mentioned above. In this study, the $\mathrm{pH} \approx 9$ (range 8.92-9.14) was selected as optimum and was used during anaerobic digestion.

The alkalised WAS samples were directed to the designed $1.2 \mathrm{~mm}$ nozzle - hydrodynamic cavitation (HC). The working pressure of the pump was $1.2 \mathrm{MPa}$ and the corresponding energy consumption of the installation amounted to $0.54 \mathrm{kWh}$. The $25 \mathrm{~L}$ of WAS (the volume used) passed through the nozzle in every $3 \mathrm{~min}$ and the capacity of the installation was $500 \mathrm{~L} / \mathrm{h}$. In fact, the disintegration process was continued for $30 \mathrm{~min}$, which corresponded to the 10 -fold flow through the cavitation nozzle (recirculation). The constructed cavitation nozzle, characterized by a diameter ratio of $b=d 0 / d 1=0.30(d 0$ - diameter narrowing; d1 - diameter of the inflow), allowed to obtain a cavitation number of $\mathrm{s}=0.245$, in selected flow conditions. Accordingly, the numerical results of the designed device turned out to be relatively efficient - the calculated pressure loss was $\Delta \mathrm{p}=74.8 \mathrm{kPa}$, while the net pressure drop $\left(\mathrm{p}_{\min } / \Delta \mathrm{p}\right)$ was almost five times greater.

\section{Sludge (WAS) two stage anaerobic digestion}

The anaerobic digestion experiments were performed in fermenters (3.0 L volume). The reactors were located in thermostatic conditions, with constant temperatures of $35 \pm 1^{\circ} \mathrm{C}$ and $55 \pm 1^{\circ} \mathrm{C}$ under mesophilic (MAD) and thermophilic (TAD) anaerobic conditions respectively. At the beginning of the process the concentration of total solids was $17.72 \pm 0.62 \mathrm{~g} / \mathrm{L}$ with volatile solids range of $57.1 \pm 1.3 \%$. The mesophilic stage (first stage) of anaerobic digestion, was conducted for 5, 7, 9, 11,13 and 15 days, and the followed thermophilic process for remaining periods of $19,17,15,13,11$ and 9 days, that was in total 24 days. Based on previous experiments, only a part, $30 \%$ in volume, of WAS was disintegrated, as described above. The disintegrated part was mixed with $40 \%$ of volume of WAS non-disintegrated and also with $30 \%$ of volume of inoculum taken from working in full scale anaerobic digesters.. The aim of inoculum added to the mixture was to bring the natural flora of fermentation microorganisms respectively for the mesophilic and thermophilic conditions. The dose of inoculum was optimized in previous studies in terms of minimising the lag-phase and decreasing the disturbance of the fermentation process (Grübel et al. 2013).

\section{Analytical methods}

All chemical analyses were performed for samples before and after each phase of disintegration and during anaerobic digestion. Total solids (TS), volatile solids (VS), and SCOD were determined following the standard methods for the examination of water and wastewater procedures $2540 \mathrm{G}$ and 5220D, respectively (APHA 2012). VS was measured in triplicate. Firstly, the sample to determine dry solid concentrations was dried at $105^{\circ} \mathrm{C}$ for $24 \mathrm{~h}$. In the next step, the dry solids were incinerated at $550^{\circ} \mathrm{C}$ for $2 \mathrm{~h}$. The resulting residue represented the inorganic part of the dry solids. The difference between the total dry solid concentration and the inorganic concentration gave the VS. To analyse the soluble phase, the particulate sludge matter was removed by centrifugation (10 min at $5000 \mathrm{rpm}$ ). The resulting supernatant was passed through membrane filters $(0.45 \mu \mathrm{m}$ pore size $)$.

For colorimetric determinations, a spectrophotometer XION 500 Dr Lange was applied. The $\mathrm{pH}$ measurement was carried out with a WTW inoLab Level2 meter, equipped with a SenTix K1 electrode for $\mathrm{pH}$.

Biogas volume produced was determined by the liquid displacement method each day. Additionally the composition of biogas $\left(\mathrm{CH}_{4}, \mathrm{CO}_{2}\right.$ and $\left.\mathrm{O}_{2}\right)$ was analysed every day of digestion with a gas analyser Gas Data GFM 416.

The results shown here were repeated 5 times and presented as mean values $\mathrm{n}=5$ and standard deviations. The estimator of the highest credibility was used for standard deviation determination (STATISTICA 6.0).

\section{Results and discussion}

\section{Hybrid WAS disintegration}

According to the given procedure, WAS disintegration was performed as hybrid method. $\mathrm{NaOH}$ (being a monobasic alkali reagent has much higher efficiency of WAS solubilisation than 
dibasic alkali reagents) was added to WAS samples in amounts sufficient to maintain a given $\mathrm{pH}$ value for $30 \mathrm{~min}$. This is in contrast to many other investigations where the increase of $\mathrm{pH}$ was continually maintained for the entire period of digestion. Short term alkalisation applied in this study resulted in cell walls weakening, which made them more susceptible to lysing processes, such as applied HC (the second-stage of pre-treatment).

The results of organic matter solubilisation, expressed as SCOD, are presented in Fig. 1. The release of SCOD at different $\mathrm{pH}$ values (alkalisation) was measured in samples after filtration (after membrane $0.45 \mu \mathrm{m}$ pore size) and centrifugation.

As shown (Fig. 1), alkalisation permits the achievement of very high solubilisation effects (measured as SCOD release). The selection of an appropriate (desired) $\mathrm{pH}$, which depends only on the dosage of $\mathrm{NaOH}$ added, is very easy. The given example shows how easy the change of the dose of $\mathrm{NaOH}$ changes the decomposition rate.

According to Lakshmi et al. (2014), the addition of $\mathrm{NaOH}$ to sludge resulted in an effective extraction of EPS, which is the sum of carbohydrate and protein. Lakshmi et al. (2014) tried to determine the efficiency of the sludge pre-treatment and obtained $6.5 \%$ COD solubilisation and $3.8 \%$ SS reduction.

The hydrodynamic disintegration of WAS was accelerated by alkalisation in this study. Additionally, Zhang et al. (2012) managed to make the two stage (hybrid) disintegration process result in a further pronounced increase in organic matter dissolution. Similar results were presented in our previous article (Grübel et al. 2013). The values of SCOD are distinctly higher than the sum of SCOD after alkalisation and HC, performed separately. Figure 2 shows SCOD increase as an example of the synergistic effect of the hybrid disintegration technology.

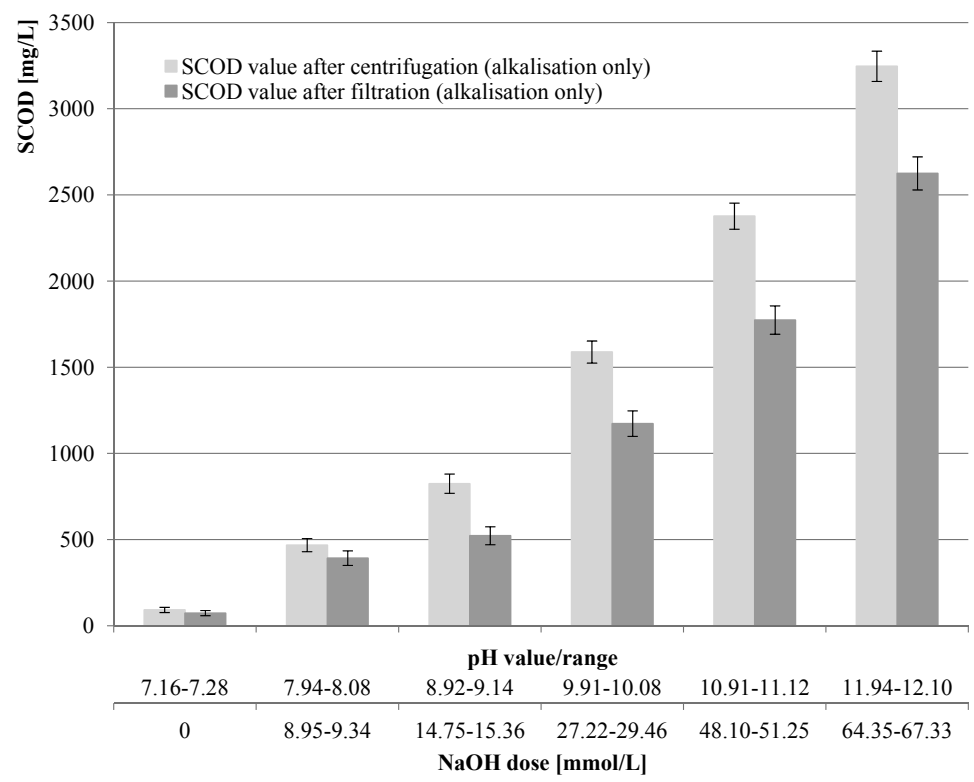

Fig. 1. Release of SCOD at different $\mathrm{pH}$ values (alkalisation) measured as filtrate and centrifugation (mean values + standard deviation)

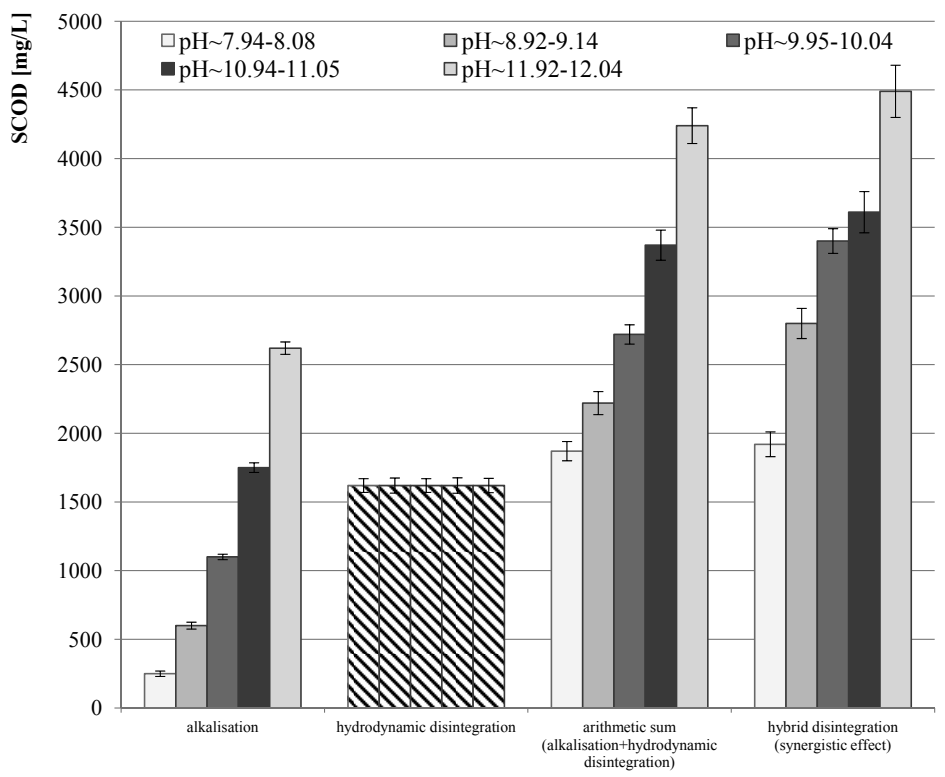

Fig. 2. Solubilisation of WAS (expressed as soluble COD) in the process of alkalisation and alkalisation plus $\mathrm{HC}$ (hydrodynamic cavitation) (mean values + standard deviation) 
In the case of very low hydrolysis intensity, only alkalisation up to $\mathrm{pH} 9$ or 10 and additionally low pressure hydrodynamic disintegration led to the solubilisation results being distinctly higher than the arithmetic sum of the two processes performed separately. The sum of SCOD after alkalisation at $\mathrm{pH} \approx 9$ (in fact, $\mathrm{pH}$ was in the range of 8.92-9.14) equalled to $600 \mathrm{mg} / \mathrm{L}$ and after $\mathrm{HC}$ amounted to $1450 \mathrm{mg} / \mathrm{L}$; in total $-2050 \mathrm{mg} / \mathrm{L}$. However, due to the synergistic effect, the obtained SCOD value was $2800 \mathrm{mg} / \mathrm{L}$. Similarly, the synergistic effect for alkalisation to $\mathrm{pH} 10$ was also approximately about $20 \%$ (Fig. 2). The synergistic effect of $20 \%$ is somewhat higher than that obtained by Lee and Han (2013) by about $16 \%$. This is probably the result of the difference in the cavitation equipment used: Lee and Han (2013) used a perforated plate, while in our experiments a nozzle was used.

The latter value constitutes an additional COD increase of over 3.5 times (for $\mathrm{pH}$ in the range of 10.94-11.05). Similarly, the synergistic effect for alkalisation to $12 \mathrm{pH}$ was also obtained.

Evidently, the simplicity of modifications and resulted effectiveness will continue after the second stage, i.e., $\mathrm{HC}$ introduction. As presented, very high organic matter solubilisation rates are easily achieved. It has to be stressed, however, that the very high WAS disintegration rate is the result of HC of already alkalised WAS, i.e. the developed hybrid hydrolysis technology. The DD was carefully determined on the basis of many tests of the hybrid technology analysed; the combination of alkalisation $-\mathrm{pH} \approx 9$, followed by $\mathrm{HC}$ for 30 minutes. The applied hybrid pre-hydrolysis resulted in a DD of $28-35 \%$.

Rani et al. (2012) investigated a similar disintegration technology. Instead of hydrodynamic disintegration, sludge samples after alkalisation were mixed using a high rpm rate (4000-24 $000 \mathrm{rpm}$ ) and dispersed. The minimum revolutions per minute for acceptable (sufficiently effective) COD solubilisation rate was above 12,000. According to Rani et al. (2012), using $\mathrm{NaOH}$ at $\mathrm{pH} 10$ in order to achieve about $30 \%$ COD solubilisation, the required specific energy in the order of $37000 \mathrm{~kJ} / \mathrm{kg}$ TS would be necessary. However, in order to get a somewhat lower COD solubilisation of $24 \%$ COD, the specific energy input will only be $4544 \mathrm{~kJ} / \mathrm{kg}$ TS. This drastic power consumption increase to upgrade the COD solubilisation from $24 \%$ to (for example) $30 \%$ is the result of the very flat solubilisation increase with energy input. Therefore, the COD solubilisation degree of $24 \%$ is considered to be the practical limit.

Lee and Han (2013) obtained a similar DD increase of about $53 \%$ for the combined treatment of alkalisation $(\mathrm{pH} \mathrm{12)}$ and hydrodynamic, ultrasonic or thermal processes. For these three combinations the lowest specific energy required value was obtained for hydrodynamic disintegration (1 $200 \mathrm{~kJ} / \mathrm{kg} \mathrm{TS}$ ). Three times higher specific energy was determined for ultrasonic (3 $600 \mathrm{~kJ} / \mathrm{kg}$ TS) pre-treatment. The thermal pre-treatment technology requires a specific energy of $72000 \mathrm{~kJ} / \mathrm{kg}$ TS.

\section{Anaerobic digestion}

After the optimisation the pre-treatment hybrid method (alkalisation + hydrodynamic cavitation), its effectiveness was investigated through carrying out a two-stage anaerobic digestion (MAD, followed by TAD) of raw and disintegrated sludge. The aim of this part of the research was to maximise the biogas production and solids degradation. It has to be stressed that according to the adopted methodology already described, hybrid disintegrated WAS amounted to only $30 \%$ in volume of the digester feed. Under such conditions, the bulk biomass $\mathrm{pH}$ present in the digester almost immediately returns to the "normal" $\mathrm{pH}$ of about 6.8 - typical for MAD and/or TAD conditions. To evaluate the efficiency of the entire process with the addition of $30 \%$ of WAS after the hybrid disintegration to fermenter, different retention times of sludge during the first and second stage of the process were applied.

Considering technological aspects and cost effectiveness, only partial WAS pre-treatment was adopted. Disintegration $(100 \%)$ of the feedstock led to a pronounced decrease of the fermentation effectiveness and digested sludge quality. Based on several factors, including high power consumption and additional chemical sludge decomposition, the hydrodynamic disintegration time of 30 min was tentatively chosen for further experiments.

As already described in the methodology, six combinations of the two stage anaerobic digestion, namely 5, 7, 9, 11, 13 and $15 \mathrm{~d}$ of MAD conditions $\left(35 \pm 1^{\circ} \mathrm{C}\right)$ and $19,17,15,13,11$ and $9 \mathrm{dTAD}$ conditions $\left(55 \pm 1^{\circ} \mathrm{C}\right)$ processes have been investigated. The results of TS and VS removal (decomposition) for these combinations have been illustrated in Figure 3. The presented data shows the mean values obtained by five series of experiments. The data presented shows the mean values plus the standard deviations.

The difference between the measured amounts of sludge before and after anaerobic digestion shows the rate of solids degradation. TS and VS were determined before and after both the MAD and TAD stage. After the tested two stages of anaerobic digestion (MAD+TAD), the highest reduction of VS concentration equalled $55.48 \%$ and was achieved for sample after 7dMAD+17dTAD (Fig. 3). Very similar results of VS removal $(52.05 \%)$ have been obtained for the combination 5dMAD+19TAD.

For a longer period of mesophilic digestion (9-15 days) a decrease of VS removal was observed, which results in calculating the biogas yield increase to be the highest (Fig. 4).

Nevertheless, assuming the biogas yield in the order of $800 \mathrm{ml} / \mathrm{g} \mathrm{VS}_{\text {removed }}$, together with the VS removal in the order of $48.66 \%$, the developed low intensive hybrid disintegration process can be considered as a very effective technology, compared for example to similar hydrodynamic WAS disintegration only. It has been noted that, in the case of all process conditions applied (different rates of digested sludge or varied DD), the content of methane in biogas produced was in the range of 62 to $66 \%$. Rani et al. (2014) observed an increase of cumulative biogas production after applying sonoalkalisation as a WAS pre-treatment, before semi-continuous mesophilic anaerobic digestion (mesophilic conditions). They concluded that the addition of $\mathrm{NaOH}$ to WAS at $\mathrm{pH} 10$ leads to the best performances in terms of COD solubilisation, SS reduction and biogas production.

The application of the low intensity WAS pre-treatment technology based on temporary alkalisation, where the selected $\mathrm{pH}$ value was held only for $30 \mathrm{~min}$, was intended to avoid a negative impact on the anaerobic digestion efficiency. In the process of the microorganisms' partial destruction, the $\mathrm{pH}$ values are always returned close to the original levels. High total ammonia concentrations can be toxic and distinctly lower 


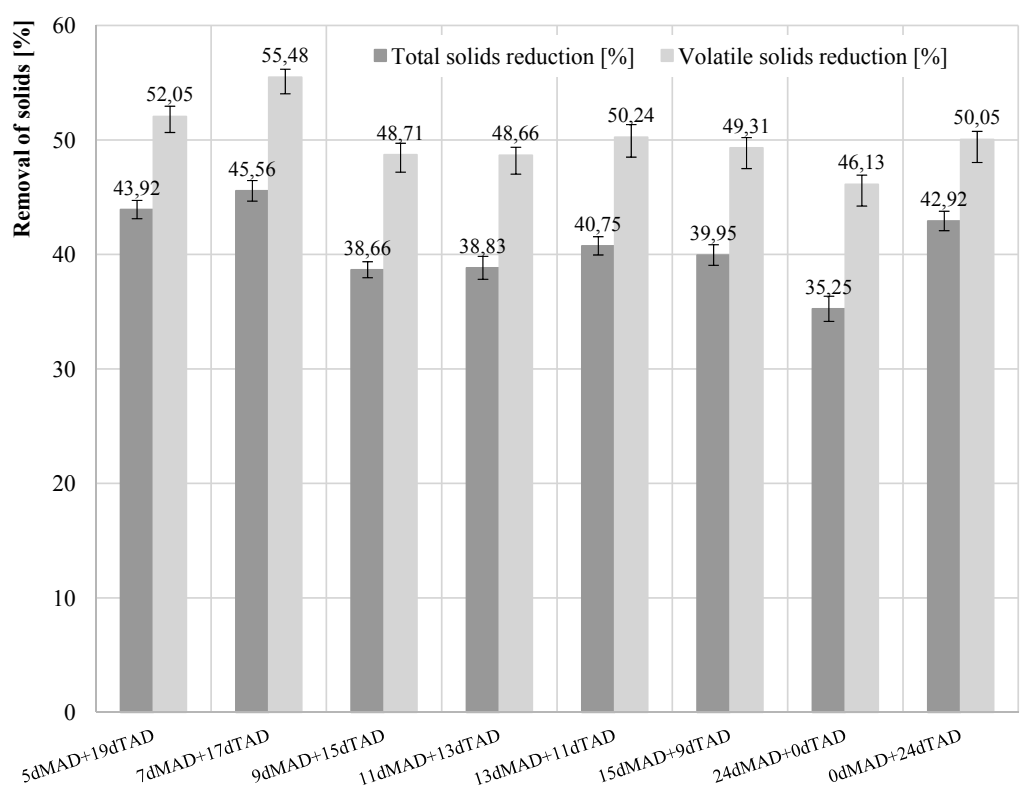

Fig. 3. Removal of volatile solids for different duration of Mesophilic Anaerobic Digestion - MAD, and Thermophilic Anaerobic Digestion - TAD (mean values + standard deviation)

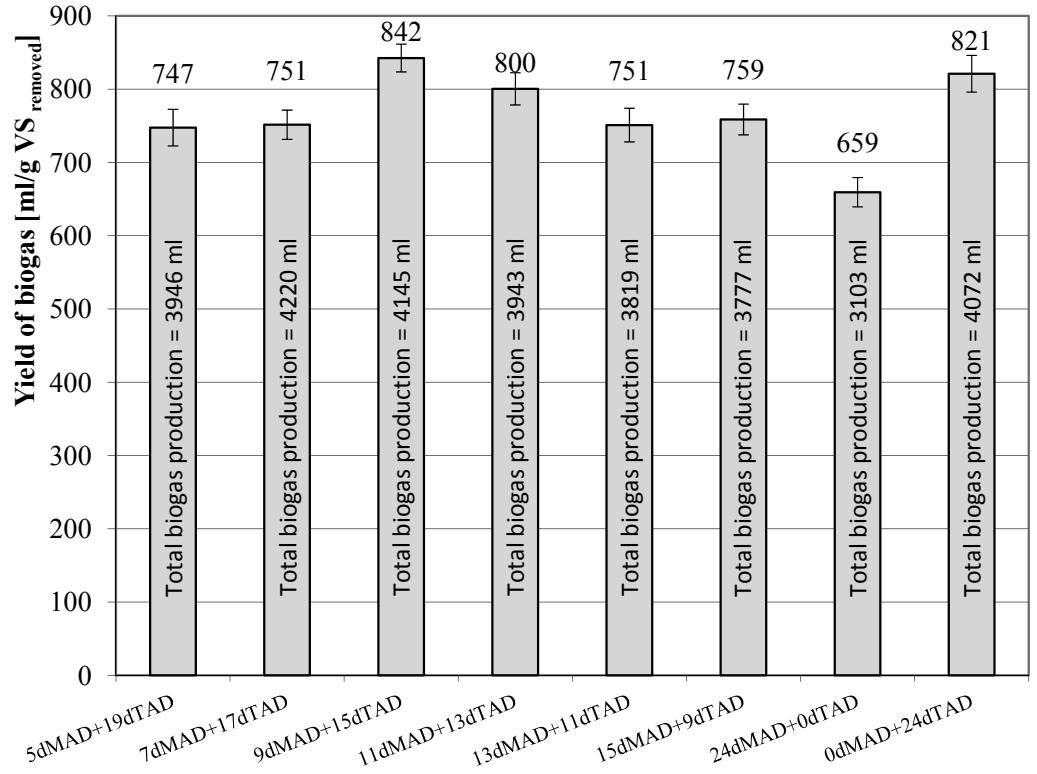

Fig. 4. Biogas yield and total biogas production for different periods of the mesophilic and thermophilic stages (mean values + standard deviation)

the digestion's effectiveness. Free ammonia $\left(\mathrm{NH}_{3}\right)$ has been suggested as the active component causing ammonia inhibition, although significantly different inhibiting concentrations are given in the literature, ranging from below $100 \mathrm{mg} \mathrm{N} / \mathrm{L}$ up to $10 \mathrm{~g} \mathrm{~N} / \mathrm{L}$ the toxic effects have been documented. This very wide range can depend on the microorganism's acclimatization, or on the actual C/N ratio, as given by Siles et al. (2010). Nevertheless, the concentration of free ammonia depends on the $\mathrm{pH}$ (increase with $\mathrm{pH}$ increase) and values in between 7 and 8 in the digester, distinctively decreasing the danger of free ammonia inhibition.

Kvesitadze et al. (2012) studied the two-stage thermophilic co-digestion of organic fraction of municipal solid waste and pre-treated corn stalk by freeze explosion. The best results of $104 \mathrm{ml} \mathrm{H}_{2} / \mathrm{g} \mathrm{VS}$ and $520 \mathrm{ml} \mathrm{CH}_{4} / \mathrm{g} \mathrm{VS}$ were obtained with alkaline $(\mathrm{pH}=9)$ pre-hydrolysis, which could increase the heat and electricity production by $23 \%$ and $26 \%$, respectively, as compared to the single stage process design.

All in all, high doses of alkali potentially upgrade the WAS pre-treatment rate and digestion efficiency, but have been proved to be a complex operation which results in an increase in investment and handling costs. In conclusion, low intensity pre-treatment technologies, as presented in this study, allow for the achievement of close to maximal overall sludge digestion efficiency, without side effects or additional work leading to high energy consumption and high investment and operational costs.

Escamilla-Alvarado et al. (2012) obtained a better energy balance with two-stage anaerobic digestion systems treating organic fraction of municipal solid wastes. However, the higher gross energetic potential was due to the higher performance in 
the methanogenic reactor rather than the hydrogen production from the first stage. Nasr et al. (2012) estimated the energy balance of two-stage anaerobic digestion of thin stillage, and concluded that optimizing the two-stage anaerobic digestion process can increase the energy balance by $18.5 \%$. Lu et al. (2008) reported that a two-stage reactor showed a better energy balance with a surplus of $2.17 \mathrm{~kJ} / \mathrm{d}$, as compared to a single stage system for treating sewage sludge.

The intension was to develop highly effective, but simple and flexible pre-treatment and digestion processes.

\section{Conclusions}

Summarising the results of performed investigations based on WAS hybrid disintegration (alkalisation plus hydrodynamic cavitation), which evoked a synergistic effect, confirmed that it is a very attractive technology.

Partial WAS pre-destructions of microorganisms in front of the two stage anaerobic digestion - mesophilic plus thermophilic process permitted organic matter (VS) reduction above $55.5 \%$ and a notable increase of biogas production i.e. the yield of $842 \mathrm{ml} / \mathrm{g} \mathrm{VS}_{\text {removed }}$. The highest total biogas production (during two stage anaerobic digestion) was observed for combination of $7 \mathrm{~d}$ MAD $+17 \mathrm{~d}$ TAD process $(4220 \mathrm{ml})$ and it was about $36 \%$ higher in comparison to $24 \mathrm{~d}$ of MAD process alone.

Reassuming the presented technology is easy to perform and gives good results. The distinct flexibility of alkalisation (easy changes of $\mathrm{pH}$ ) allows for upgrading of the effects of hydrodynamic disintegration, i.e. the development of a flexible technology.

In conclusion, the developed hybrid pre-treatment technology is characterised by low chemicals and power consumption and can be classified as a low intensive, highly effective (accelerated) technology of WAS anaerobic digestion.

\section{Acknowledgements}

This work was supported by the EU ROUTES project (Contract No 265156, FP7 2007-2013, THEME [ENV.2010.3.1.1-2] Innovative system solutions for municipal sludge treatment and management).

\section{References}

APHA (2012) Standard Methods for the Examination of Water and Wastewater, 22nd ed. American Public Health Association, American Water Works Association, Water Environment Federation, Washington, DC, USA.

Ariunbaatar, J., Panico, A., Esposito, G., Pirozzi, F. \& Lens, P.N.L. (2014). Pretreatment methods to enhance anaerobic digestion of organic solid waste, Applied Energy, 123, pp. 143-156.

Carrère, H., Dumas, C., Battimelli, A., Batstone, D.J., Delgenes, J.P., Steyer, J.P. \& Ferrer, I. (2010). Pretreatment methods to improve sludge anaerobic degradability: A review, Journal of Hazardous Materials, 183, pp. 1-15.

Chen, Y., Jiang, S., Yuan, H., Zhou, Q. \& Gu, G. (2007). Hydrolysis and acidification of waste activated sludge at different $\mathrm{pHs}$, Water Research, 41, pp. 683-689.

Climent, M., Ferrer, I., Baeza, M.M., Artola, A., Vazquez, F. \& Font, X. (2007). Effect of thermal and mechanical pretreatments of secondary sludge on biogas production under thermophilic conditions, Chemical Engineering Journal, 133, pp. 335-342.
Dwyer, J., Starreburg, D., Tait, S., Barr, K., Batstone, D.J. \& Lant, P. (2008). Decreasing activated sludge thermal hydrolysis temperature reduces product colour, without decreasing degradability, Water Research, 42, pp. 4699-4709.

Escamilla-Alvarado, C., Rios-Leal, E., Ponce-Noyola, M.T. \& Poggi-Varaldo, H.M. (2012). Gas biofuels from solid substrate hydrogenogenic-methanogenic fermentation of the organic fraction of municipal solid waste, Process Biochemistry, 47, pp. 1572-1587.

Grübel, K., Machnicka, A. \& Wacławek, S. (2013). Impact of alkalization of surplus activated sludge on biogas production, Ecological Chemistry and Engineering S, 20, pp. 343-351.

Kalogo, Y. \& Monteith, H. (2008). State of science report: Energy and resource recoverable from sludge, Global Water Research Coalition, UKWIR, WERF, STOWA.

Kim, J., Park, C., Kim, T-H., Lee, M., Kim, S., Kim, S-W. \& Lee, J. (2003). Effects of various pretreatments for enhanced anaerobic digestion with waste activated sludge, Journal of Bioscience and Bioengineering, 95, pp. 271-275.

Kvesitadze, G., Sadunishvili, T., Dudauri, T., Zakariashvili, N., Partshaladze, G., Ugrekhelidze, V., Tsiklauri, G., Metreveli, B. \& Jobavae, M. (2012). Two-stage anaerobic process for bio-hydrogen and biomethane combines production from biodegradable solid waste, Energy, 37, pp. 94-102.

Kopp, J. \& Ewert, W. (2006). New Processes for the improvement of sludge digestion and sludge dewatering, Aqua Enviro/ CIWEM 11th Biosolids and Organic Residuals Conference, Wakefield, UK. [http://www.cambi.no/photoalbum/view2/ P3NpemU9b3JnJmlkPTIyMDAyMCZ0e-XBIPTE]

Lakshmi, M.V., Merrylin, J., Kavitha, S., Kumar, S.A., Banu, J.R. $\&$ Yeom, I-T. (2014). Solubilization of municipal sewage waste activated sludge by novel lytic bacterial strains, Environmental Science and Pollution Research, 21, pp. 2733-2743.

Lee, I. and Han, J.-I. (2013). The effects of waste-activated sludge pretreatment using hydrodynamic cavitation for methane production, Ultrasonics Sonochemistry, 20, pp. 1450-1455.

Li, H., Jin, Y., Mahar, R.B., Wang, Z. \& Nie, Y. (2008). Effects and model of alkaline waste activated sludge treatment, Bioresource Technology, 99, pp. 5140-5144.

Li, H., Li, CH., Liu, W. \& Zou, S.H. (2012). Opitimized alkaline pretreatment of sludge before anaerobic digestion, Bioresource Technology, 123, pp. 189-194

Li, H., Zou, S., Li, C. \& Jin, Y. (2013). Alkaline post-treatment for improved sludge anaerobic digestion, Bioresource Technology, 140, pp. 187-191.

Lu, J., Gavala, H.N., Skiadas, I.V., Mladenovska, Z. \& Ahrin, B.K. (2008). Improving anaerobic sewage sludge digestion by implementation of a hyper-thermophilic prehydrolysis step, Journal of Environmental Management, 88, pp. 881-889.

Nasr, N., Elbeshbishy, E., Hafez, H., Nakhla, G., Hesham, E.L. \& Naggar, M. (2012). Comparative assessment of single-stage and two-stage anaerobic digestion for the treatment of thin stillage, Bioresource Technology, 111, pp. 122-126.

Penaud, V., Delgenes, J.P., Moletta, R., Colas, G., Vanhoutte, B. \& Cans, P. (2000). Influence of thermo-chemical solubilization of a microbial biomass on solubilzation and biodegradability performance, Environmental Technology, 21, pp. 87-96.

Rafique, R., Poulsen, T.G., Nizamia, A-S., Asamc, Z-Z., Murphya, J.D. \& Kielya, G. (2010). Effect of thermal, chemical and thermo-chemical pre-treatments to enhance methane production, Energy, 35, pp. 4556-4561.

Rani, R.U., Kumar, S.A., Kaliappan, S. \& Banu, J.R. (2012). Combined treatment of alkaline and disperser for improving solubilization and anaerobic biodegradability of dairy waste activated sludge, Bioresource Technology, 126, pp. 107-116.

Sakiyama, T., Nanasaki, Y., Hagiwara, T. \& Watanabe, H. (2011). Removability of bacterial spores from solid surfaces during 
cleaning. International Congress on Engineering and Food (ICEF), 22-26 Athens, Greece 2011.

Silva, M.P., Pereira, C.A., Junqueira, J.C. \& Jorge, A.O.C. (2013). Methods of destroying bacterial spores, In: Microbial pathogens and strategies for combating them: science, technology and education, Méndez-Vilas A. (ed.), Formatex Research Center, 1, pp. 490-496.

Şahinkaya, S. \& Sevimli, M.F. (2013). Effects and modelling of ultrasonic waste-activated sludge disintegration, Water and Environment Journal, 27, pp. 238-246.

Sambusiti, C., Monlau, F., Ficara, E., Carrère, H. \& Malpei, F. (2013). A comparison of different pre-treatments to increase methane production from two agricultural substrates, Applied Energy, 104, pp. 62-70.
Siles, J.A., Brekelmans, J., Martin, M.A., Chica, A.F. \& Martin, A. (2010). Impact of ammonia and sulphate concentration on thermophilic anaerobic digestion, Bioresource Technology, 101, pp. 9040-9048.

Wang, X., Duan, X., Chen, J., Fang, K., Feng, L., Yan, Y. \& Zhou, Q. (2016). Enhancing anaerobic digestion of waste activated sludge by pretreatment: effect of volatile to total solids, Environmental Technology, 8, pp. 1-10.

Watcharapol, W. \& Wichitsathian, B. (2014). Alkaline pretreatment of waste activated sludge in anaerobic digestion, Journal of Clean Energy Technologies, 2, pp. 118-121.

Zhang, Y, Zhang, P, Zhang, G, Ma, W, Wu, H. \& Ma, B. (2012) Sewage sludge disintegration by combined treatment of alkaline plus high pressure homogenization, Bioresource Technology, 123, pp. 514-519. 